\title{
Synthesis, characterization and gas separation properties of novel polyimides containing cardo and tert-butyl-m-terphenyl moieties
}

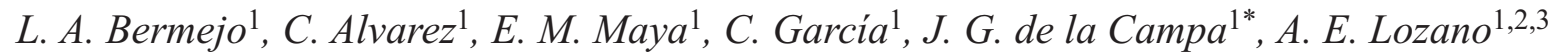 \\ ${ }^{1}$ Instituto de Ciencia y Tecnología de Polímeros, ICTP-CSIC, Juan de la Cierva 3, E-28006 Madrid, Spain \\ ${ }^{2}$ SMAP, UA-UVA_CSIC, Associated Research Unit to CSIC. Univ. de Valladolid, Fac. de Ciencias, Paseo Belén 7, \\ E-47011 Valladolid, Spain \\ ${ }^{3}$ IU CINQUIMA, Univ. de Valladolid, Paseo Belén 5, E-47011 Valladolid, Spain
}

Received 17 November 2017; accepted in revised form 15 January 2018

\begin{abstract}
A series of aromatic polyimides has been obtained by the reaction of two dianhydrides, the commercial 2,2'bis(3,4-dicarboxyphenyl)hexafluoropropane dianhydride $(6 F D A)$ and another having a 5 '-tert-butyl-m-terphenyl moiety $(B T P D A)$, with several diamines, including two that have a cardo structure (derived from 9H-fluorene), one of them bearing methyl groups ortho to the amino functionalities (TMeCardo). The solubility, and also the thermal, mechanical, and gas separation properties of the corresponding polyimide membranes were evaluated and compared in order to explore the effect of the different groups in the polyimide backbone. The novel polyimides, which were derived from BTPDA and the cardo diamines, showed high thermal stability, excellent solubility in organic solvents and good gas separation properties, especially the polyimide that bore the ortho methyl substituents. The behavior was especially good for the pair $\mathrm{O}_{2} / \mathrm{N}_{2}$, where the TMeCardo polymer overpassed the Robeson upper bound.
\end{abstract}

Keywords: polymer membranes, polyimide, taylor made polymers, structure-properties relationships

\section{Introduction}

Aromatic polyimides are considered as high performance polymers due to their excellent thermal, mechanical and dielectric properties [1-3]. Among their applications, gas separation by polyimide membranes has been proven as an alternative technology to conventional separation methods like cryogenic distillation or absorption [4-7]. Due to their high rigidity, aromatic polyimides show high gas selectivity and, because of that, the gas transport properties of a large number of polyimides have been investigated [8-10]. A good membrane has to show high permeability, and this is usually attained, in glassy polymers, by means of structural changes that make difficult the molecular packing and increase the free volume $[11,12]$. The introduction of bulky pendent groups [13-16], which prevent the close packing of the chains, has been shown as a very efficient method to increase the fractional free volume (FFV) and consequently to enhance the gas permeability. Among the bulky pendent groups introduced into polyimides, tert-butyl groups have shown to be very effective units to improve FFV without detriment of thermal stability or processability $[9,17-19]$.

It is well known that an important drawback of polyimides is their poor solubility, which makes difficult their processing as membranes. For this reason, a goal in polyimide chemistry is to improve the solubility in organic solvents without a loss of the above-mentioned properties. Thus, several synthetic

"Corresponding author, e-mail: jcampa@ictp.csic.es (C) BME-PT 
modifications of the polyimide structure, such as introduction of flexible linkages [20], bulky pendent groups [21-23] or asymmetric monomers [24, $25]$ have been extensively adopted to address this problem.

The aromatic cardo polymers (from Latin loop) possess excellent thermal and chemical stability, excellent solubility and good mechanical and dielectric properties [26]. The cardo moiety imparts also a significant increase in $T_{\mathrm{g}}$ and thermal stability [27-30]. Additionally, the aromatic cardo polyimides reported in the literature exhibit high gas selectivity values $[23,31,32]$.

According to these observations, the target of this work was to prepare novel polyimides containing tert-butyl or hexafluoroisopropylidene groups and cardo moieties in the repeat unit (Figure 1) and to explore their effect on solubility, thermal stability and gas separation properties. The properties have been compared with those of polyimides from the same dianhydrides and other diamines with orthomethyl groups, to establish relationships between structure and properties. Our strategy involved the reaction between a dianhydride that bears a tert-butyl substituent, the 5'-tert-butyl-m-terphenyl-3,3",4,4"tetracarboxylic acid dianhydride, which has been previously used by us, and several diamines. The cardo diamines chosen for this study were 9,9-bis(4-aminophenyl)-fluorene (Cardo) and 9,9-bis(4-amino-3,5-dimethylphenyl)-fluorene (TMeCardo) which offered
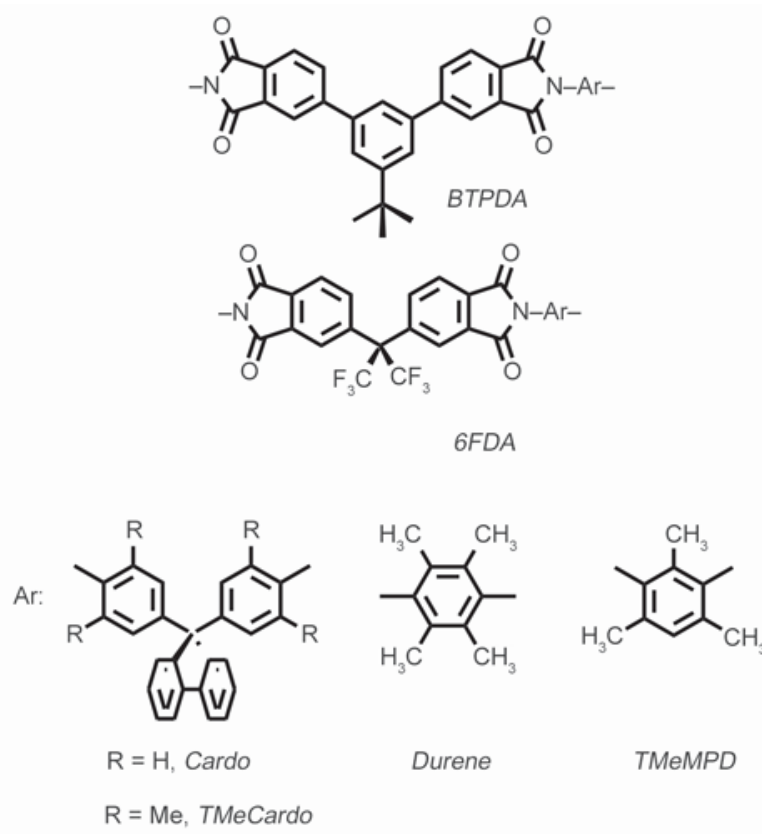

Figure 1. Structure and designation of the polyimides studied in this work. us the opportunity to determine the additional effects of the ortho methyl groups on the polyimide properties, particularly related to their gas separation properties. Moreover, other two diamines with ortho methyl groups: durene and trimethyl-m-phenylene diamine (TMeMPD), well known for providing excellent gas separation properties to the polyimides, have been made to react with the $B T P D A$ dianhydride.

To explore the effect of the introduction of the tertbutyl pendant groups in the repeat unit, the properties of the novel polyimides have been compared with those of polyimides, which were taken as reference, based on the same diamines and the known dianhydride $6 F D A$, which yields polyimides with excellent gas separation properties.

\section{Experimental}

\subsection{Materials}

Solvents and other reactants were of reagent grade quality and were used as received. 9,9-bis (4-aminophenyl) fluorene (Cardo) was provided by Chriskev. Durene and trimethyl-m-phenylene diamine were provided by Sigma-Aldrich. 2,2'-bis (3,4-dicarboxyphenyl) hexafluoropropane dianhydride ( $6 F D A$ ) was provided by Fluorochem. All commercial monomers were sublimated before use.

5'-tert-butyl-m-terphenyl-3,3",4,4"-tetracarboxylic acid dianhydride (BTPDA) was synthesized according to the procedure previously reported [33].

\subsection{Monomer synthesis}

9,9-Bis (4-amino-3,5-dimethylphenyl) fluorene (TMeCardo) was synthesized from 2,6-dimethylaniline (Sigma-Aldrich) and 9-fluorenone (SigmaAldrich) in the presence of trifluoromethanesulfonic acid (Sigma-Aldrich), according to the following procedure: $24.6 \mathrm{~g}(0.203 \mathrm{~mol})$ of 2,6-dimethylaniline were mixed with $25 \mathrm{~mL}$ of concentrated hydrochloric acid and $12 \mathrm{~mL}$ of water. Then, $12.2 \mathrm{~g}(0.068 \mathrm{~mol})$ of fluorenone, $6 \mathrm{~mL}$ of trifluoromethanesulfonic acid and $1 \mathrm{~mL}$ of mercaptopropionic acid were added to the mixture. The solution was put into an autoclave and heated at $150^{\circ} \mathrm{C}$ overnight. The crude obtained was washed with a solution of sodium hydroxide, obtaining a slurry that was filtered and acidified with hydrochloric acid. Then, acetone was added to remove the excess of 2,6-dimethylaniline. The remaining solid, in the form of diamine hydrochloride was treated in aqueous ammonia medium. Finally, the product was dried and recrystallized twice from 
toluene, to yield a monomer grade 9,9-bis (4-amino3,5-dimethylphenyl) fluorene in $83 \%$ yield. Melting point (DSC): $319^{\circ} \mathrm{C}$. Elemental analysis $\left(\mathrm{C}_{29} \mathrm{H}_{28} \mathrm{~N}_{2}\right)$ : Calc: C $86.10 \%$; H $6.98 \%$ N 6.92\%, Found: C $85.01 \%$; H 7.70\%; N 7.29\%.

${ }^{1} \mathrm{H}-\mathrm{NMR}$ (DMSO- $\left.d_{6}, 300 \mathrm{MHz}, \mathrm{ppm}\right): 7.83(d, 2 \mathrm{H})$; $7.31(\mathrm{~m}, 6 \mathrm{H}) ; 6.54(\mathrm{~s}, 4 \mathrm{H}) ; 4.40($ broad s, 4H); 1.92 (s, $12 \mathrm{H})$.

\subsection{Synthesis of polyimides}

All polyimides were prepared in a similar way, by one-step imidization in $m$-cresol, according to the following procedure.

A $100 \mathrm{~mL}$ three-necked flask with mechanical stirring and nitrogen inlet was charged with $3.0 \mathrm{mmol}$ of the diamine and $20 \mathrm{~mL}$ of $m$-cresol. After complete solution, $3.0 \mathrm{mmol}$ of the corresponding dianhydride was added to the solution. The temperature was gradually increased to $80^{\circ} \mathrm{C}$ and then $0.2 \mathrm{~mL}$ of pyridine was added. The reaction was held at that temperature for $2 \mathrm{~h}$. The temperature was then risen up to $180^{\circ} \mathrm{C}$ and $4.0 \mathrm{mmol}$ of benzoic acid was added. The reaction was maintained at that temperature overnight. After cooling to room temperature, the viscous solution was poured into methanol. Subsequently, the polymer was filtered out and extracted with ethanol in a Soxhlet for $8 \mathrm{~h}$, and finally dried in a vacuum oven at $90^{\circ} \mathrm{C}$ overnight. Yields were nearly quantitative for all polymerizations.

BTPDA-Cardo: ${ }^{1} \mathrm{H}-\mathrm{NMR}\left(300 \mathrm{MHz}, \mathrm{CDCl}_{3}\right): \delta=$ 8.20 (s, 2H), 8.03 (m, 4H), 7.79 (d, 2H), 7.73 (s, 2H), $7.71(\mathrm{~s}, 1 \mathrm{H}), 7.46(\mathrm{~d}, 2 \mathrm{H}), 7.40-7.30(\mathrm{~m}, 12 \mathrm{H}), 1.48(\mathrm{~s}$, 9H, Me).

${ }^{13} \mathrm{C}-\mathrm{NMR}\left(75 \mathrm{MHz}, \mathrm{CDCl}_{3}\right): \delta=167.2$ and 167.0 (NCO), 153.5, 150.3, 147.7 and 145.4, 140.1, 139.9, $136.6,133.2,130.3,130.2,127.9-128.9,126.4$, 126.1, 125.1, 124.3, 122.5, 120.3, 65.0, 35.2, 31.0. IR (film, $\mathrm{cm}^{-1}$ ): 2960-2850 (C-H aliph. st.), 1712 and $1775(\mathrm{C}=\mathrm{O}$ imide st. $), 1500(\mathrm{C}=\mathrm{C}$ arom. $), 1358$ (C-N-C st.), $1080(\mathrm{C}-\mathrm{H} \delta)$.

BTPDA-TMeCardo: ${ }^{1} \mathrm{H}-\mathrm{NMR}\left(300 \mathrm{MHz}, \mathrm{CDCl}_{3}\right)$ : (See Figure 2) $\delta=8,20\left(\mathrm{~s}, 2 \mathrm{H}, \mathrm{H}_{\mathrm{e}}\right) ; 8,05\left(\mathrm{~m}, 4 \mathrm{H}, \mathrm{H}_{\mathrm{b}}\right.$, $\left.\mathrm{H}_{\mathrm{c}}\right) ; 7,79\left(\mathrm{~d}, 2 \mathrm{H}, \mathrm{H}_{\mathrm{t}} ; 7,75\left(\mathrm{~s} 2 \mathrm{H}, \mathrm{H}_{\mathrm{i}}\right) ; 7,73\left(\mathrm{~s}, 1 \mathrm{H}, \mathrm{H}_{\mathrm{h}}\right)\right.$; 7,49 (d, 2H, $\mathrm{H}_{\mathrm{x}} ; 7,41\left(\mathrm{t}, 2 \mathrm{H}, \mathrm{H}_{\mathrm{u}}\right) ; 7,34\left(\mathrm{t}, 2 \mathrm{H}, \mathrm{H}_{\mathrm{v}}\right)$; $7,07\left(\mathrm{~s}, 4 \mathrm{H}, \mathrm{H}_{\mathrm{o}}\right) ; 2,10\left(\mathrm{~s}, 12 \mathrm{H}, \mathrm{H}_{\mathrm{y}}\right) ; 1,46\left(\mathrm{~s}, 9 \mathrm{H}, \mathrm{H}_{\mathrm{l}}\right)$.

${ }^{13} \mathrm{C}-\mathrm{NMR}\left(75 \mathrm{MHz}, \mathrm{CDCl}_{3}\right.$ ): (See Figure 2) $\delta=167.2$ and $167.1(\mathrm{NCO}), 153.5\left(\mathrm{C}_{\mathrm{j}}\right), 150.5\left(\mathrm{C}_{\mathrm{d}}\right), 147.7$ and $146.7\left(\mathrm{C}_{\mathrm{s}}\right.$ and $\left.\mathrm{C}_{\mathrm{r}}\right), 140.1$ and $140.0\left(\mathrm{C}_{\mathrm{g}}\right.$ and $\left.\mathrm{C}_{\mathrm{m}}\right), 136.5$ $\left(\mathrm{C}_{\mathrm{p}}\right) 133.1\left(\mathrm{C}_{\mathrm{c}}\right), 132.8(\mathrm{Ca}), 130.6\left(\mathrm{C}_{\mathrm{f}}\right), 128,4\left(\mathrm{C}_{\mathrm{o}}\right)$,
$128.1\left(\mathrm{C}_{\mathrm{n}}\right), 127.6$ and $127.9\left(\mathrm{C}_{\mathrm{u}}, \mathrm{C}_{\mathrm{v}}\right), 126.6\left(\mathrm{C}_{\mathrm{t}}\right), 125.1$ (Ci), $124.3\left(\mathrm{C}_{\mathrm{b}}\right), 124.0\left(\mathrm{C}_{\mathrm{h}}\right), 122.5\left(\mathrm{C}_{\mathrm{e}}\right), 120,1\left(\mathrm{C}_{\mathrm{x}}\right)$, $76.55\left(\mathrm{C}_{\mathrm{q}}\right), 35.2\left(\mathrm{C}_{\mathrm{k}}\right), 31,4\left(\mathrm{C}_{\mathrm{l}}\right), 18,3\left(\mathrm{C}_{\mathrm{y}}\right)$.

IR (film, $\mathrm{cm}^{-1}$ ): 2960-2850 (C-H aliph. st.), 1780 and $1706(\mathrm{C}=\mathrm{O}$ imide st.), $1485(\mathrm{C}=\mathrm{C}$ arom. $), 1360$ $(\mathrm{C}-\mathrm{N}-\mathrm{C}$ st. $), 1095(\mathrm{C}-\mathrm{H} \delta), 730(\mathrm{C}=\mathrm{O}$ imide $\delta)$.

BTPDA-Durene: ${ }^{1} \mathrm{H}-\mathrm{NMR}$ (300 MHz, DMSO-d6 $\left.90^{\circ} \mathrm{C}\right): \delta=8.22(\mathrm{~s}, 2 \mathrm{H}), 8.07(\mathrm{~m}, 4 \mathrm{H}), 7.76(\mathrm{~s}, 2 \mathrm{H})$, 7.30 (s, 1H, $\mathrm{H}_{\mathrm{Ar}}$ ), 2.12 (s, 6H, Me), 1.90 (s, 3H, Me), $1.51(\mathrm{~s}, 9 \mathrm{H})$.

IR (film, $\mathrm{cm}^{-1}$ ): 2960-2855 (C-H aliph. st.), 1776 and 1714 ( $\mathrm{C}=\mathrm{O}$ imide st.), 1344 (C-N-C st.), $1095(\mathrm{C}-\mathrm{H}$ $\delta), 750(\mathrm{C}=\mathrm{O}$ imide $\delta)$.

\subsection{Preparation of membranes}

Polyimide membranes were prepared by casting 7\% $(w / v)$ filtered $m$-cresol solutions of the polymers onto a glass plate that was left at $80^{\circ} \mathrm{C}$ overnight. Then, the films were dried in a vacuum oven at $100^{\circ} \mathrm{C} / 24 \mathrm{~h}$, $180^{\circ} \mathrm{C} / 1 \mathrm{~h}$, and $250^{\circ} \mathrm{C} / 30 \mathrm{~min}$. Film thicknesses were between 30 and $50 \mu \mathrm{m}$.

\subsection{Measurements}

${ }^{1} \mathrm{H}$ and ${ }^{13} \mathrm{C}$-NMR spectra were recorded on a Varian Gemini 300 spectrometer operating at 30 and $75 \mathrm{MHz}$ respectively. Fourier Transform Infrared Spectra (FT-IR) of polymer films were recorded on a Perkin Elmer RX-I instrument.

Differential scanning calorimetry (DSC) analyses were performed on a TA-Q2000 under nitrogen at a $20^{\circ} \mathrm{C} /$ min scan rate. Thermogravimetric analyses (TGA) were recorded on a TA-Q500 analyzer from $5-10 \mathrm{mg}$ of sample under a $50 \mathrm{~mL} / \mathrm{min}$ nitrogen flux at $10^{\circ} \mathrm{C} / \mathrm{min}$.

Inherent viscosities were measured at $25^{\circ} \mathrm{C}$ with an Ubbelohde viscometer using NMP as solvent at $0.5 \mathrm{~g} / \mathrm{dL}$ concentration.

The polymers solubility was determined by mixing $10 \mathrm{mg}$ of polymer with $1 \mathrm{~mL}$ of solvent, followed by stirring for $24 \mathrm{~h}$ at room temperature. Then, the samples that were not soluble at room temperature were heated.

Density was determined using a XS105 Dual Range Mettler Toledo balance coupled with a density kit based on Archimedes' principle. The samples were weighed in air and into a known-density liquid (high purity isooctane). The measurements were performed at room temperature and the densities were calculated from (Equation (1): 
$\rho_{\text {sample }}=\rho_{\text {liquid }} \frac{W_{\text {air }}-W_{\text {liquid }}}{W_{\text {air }}}$

where $W_{\text {air }}$ is the weight of the sample in air, $W_{\text {liquid }}$ is the weight in isooctane and $\rho_{\text {liquid }}$ is the density of isooctane.

The density data were used to evaluate chain packing using the fractional free volume $(F F V)$, which was calculated using Equation (2):

$F F V=\frac{V_{\mathrm{e}}-1.3 V_{\mathrm{w}}}{V_{\mathrm{e}}}$

where $V_{\mathrm{e}}$ is the polymer specific volume and $V_{\mathrm{W}}$ is the van der Waals volume, which was obtained by molecular modeling using the semi-empirical method Austin Model 1 (AM1) in the Hyperchem computer program, version 8.0.3 [34, 35].

Gas permeation properties were determined for single gas feeds using a constant volume/variable pressure apparatus at $30^{\circ} \mathrm{C}$. The initial downstream pressure was maintained below $10^{-2} \mathrm{mbar}$, while the upstream pressure was kept at 3.0 bar for all gases. Helium permeation tests at three upstream pressures (1, 3 and 5 bar) were carried out to check the absence of pinholes. Permeability values $(P)$ were determined from the slope of downstream pressure vs. time $(\mathrm{d} p(t) / \mathrm{d} t)$, plotted when steady state had been achieved. $P$ was expressed in Barrer

$\left[1\right.$ Barrer $=10^{-10}\left(\mathrm{~cm}^{3}(\mathrm{STP}) \cdot \mathrm{cm}\right) /\left(\mathrm{cm}^{2} \cdot \mathrm{s} \cdot \mathrm{cmHg}\right)=$ $3.346 \cdot 10^{-16} \mathrm{~mol} \cdot \mathrm{m} / \mathrm{m}^{2} \cdot \mathrm{s}$ Pa (SI units)]. The ideal selectivity for a pair of gases $A$ and $B$ was calculated from the ratio of their pure gas permeabilities $P_{\mathrm{A}}$ and $P_{\mathrm{B}}$ using Equation (3):

$\alpha_{\mathrm{A} / \mathrm{B}}=\frac{P_{\mathrm{A}}}{P_{\mathrm{B}}}$

\subsection{Computational methods}

Computational studies were carried out by initially optimizing the structures at the AM1 level of theory [34]. Subsequently, electronic energies and structures were calculated by full optimization, without any geometrical constraint, by using the Becke's threeparameter hybrid functional and the Lee et al. correlation functional with the $6-31 \mathrm{G}+(\mathrm{d}, \mathrm{p})$ basis set. HOMO energies, zero-point electronic energies were determined by doing a single-point calculation with the hybrid B3LYP/6-31G+(d,p) [35]. The Gaussian 09 v.A1 and Gaussview v.5.08 program packages were used throughout this work. Molecular graphs and pictures were achieved with the Gauss View and Arguslab programs.

Rotational barriers, around the $N_{\text {imide }}-\mathrm{C}_{\mathrm{Ar}}$ bond for BTPDA-Cardo and BTPDA-TMeCardo were calculated by AM1 by fixing the dihedral angle at certain angles.

\section{Results and discussion}

\subsection{Polymers syntheses and characterization}

It is well established in the synthesis of polyimides that the reactivity of diamines is controlled by their HOMO energy and by the electronic density on the nitrogen atoms, whereas the reactivity of the dianhydrides is controlled by their LUMO energy and by the electronic density on the carbonyl carbons, although the electronic densities play, in both cases, a minor role in this kind of reaction. Thus, the polymerization feasibility can be predicted by the $\mathrm{LUMO}_{\text {dianhydride }}-$ $\mathrm{HOMO}_{\text {diamine }}$ energy difference. It can be said that the reactivity is higher when the energies of $\mathrm{LUMO}_{\text {dianhydride }}$ and $\mathrm{HOMO}_{\text {diamine }}$ are closer and, consequently, the probability of attaining high molecular weight polymers is higher. The energy values, calculated in this work for the different monomers, are shown in Table 1.

Table 1. Electronic parameters (B3LYP/631G*) of monomers.

\begin{tabular}{|l|c|c|c|c|}
\hline \multicolumn{1}{|c|}{ Monomer } & $\begin{array}{c}\boldsymbol{E}_{\text {LUMO }} \\
{[\mathbf{e V}]}\end{array}$ & $\begin{array}{c}\boldsymbol{E}_{\mathrm{HOMO}} \\
{[\mathbf{e V}]}\end{array}$ & $\begin{array}{c}\Delta \boldsymbol{E} \boldsymbol{B T P D} \boldsymbol{A} \text {-amine } \\
{[\mathbf{e V}]^{*}}\end{array}$ & $\begin{array}{c}\Delta \boldsymbol{E} \boldsymbol{F} \boldsymbol{A} \text {-amine } \\
{[\mathbf{e V}]^{*}}\end{array}$ \\
\hline BTPDA & -2.80 & - & - & - \\
\hline 6FDA & -3.11 & - & - & 2.06 \\
\hline Cardo & - & -5.17 & 2.37 & 1.91 \\
\hline TMeCardo & - & -5.02 & 1.59 & 1.28 \\
\hline TMeMPD & - & -4.39 & 1.63 & 1.32 \\
\hline Durene & - & -4.43 & & - \\
\hline
\end{tabular}

${ }^{*} \Delta E$ denotes the orbital energy difference between the aromatic diamine HOMO and the aromatic dianhydride LUMO $(\Delta E=$ $\left.E_{\mathrm{LUMO}}-E_{\mathrm{HOMO}}\right)$. 
The LUMO energies of BTPDA and $6 F D A$ are higher than the LUMO energies of more common commercial dianhydrides: 3,3', 4,4'-oxydiphenyltetracarboxylic dianhydride $\left(E_{\mathrm{LUMO}}=-2.95 \mathrm{eV}\right), 3,3^{\prime}$, 4,4'-sulfonyldiphenyltetracarboxylic dianhydride
$\left(E_{\mathrm{LUMO}}=-3.54 \mathrm{eV}\right)$ and pyromellitic dianhydride $\left(E_{\mathrm{LUMO}}=-3.94 \mathrm{eV}\right)$. Therefore, the reactivity of BTPDA and $6 F D A$ is among the lowest, but it is high enough to permit successful reaction with aromatic diamines giving high molecular weight polymers.
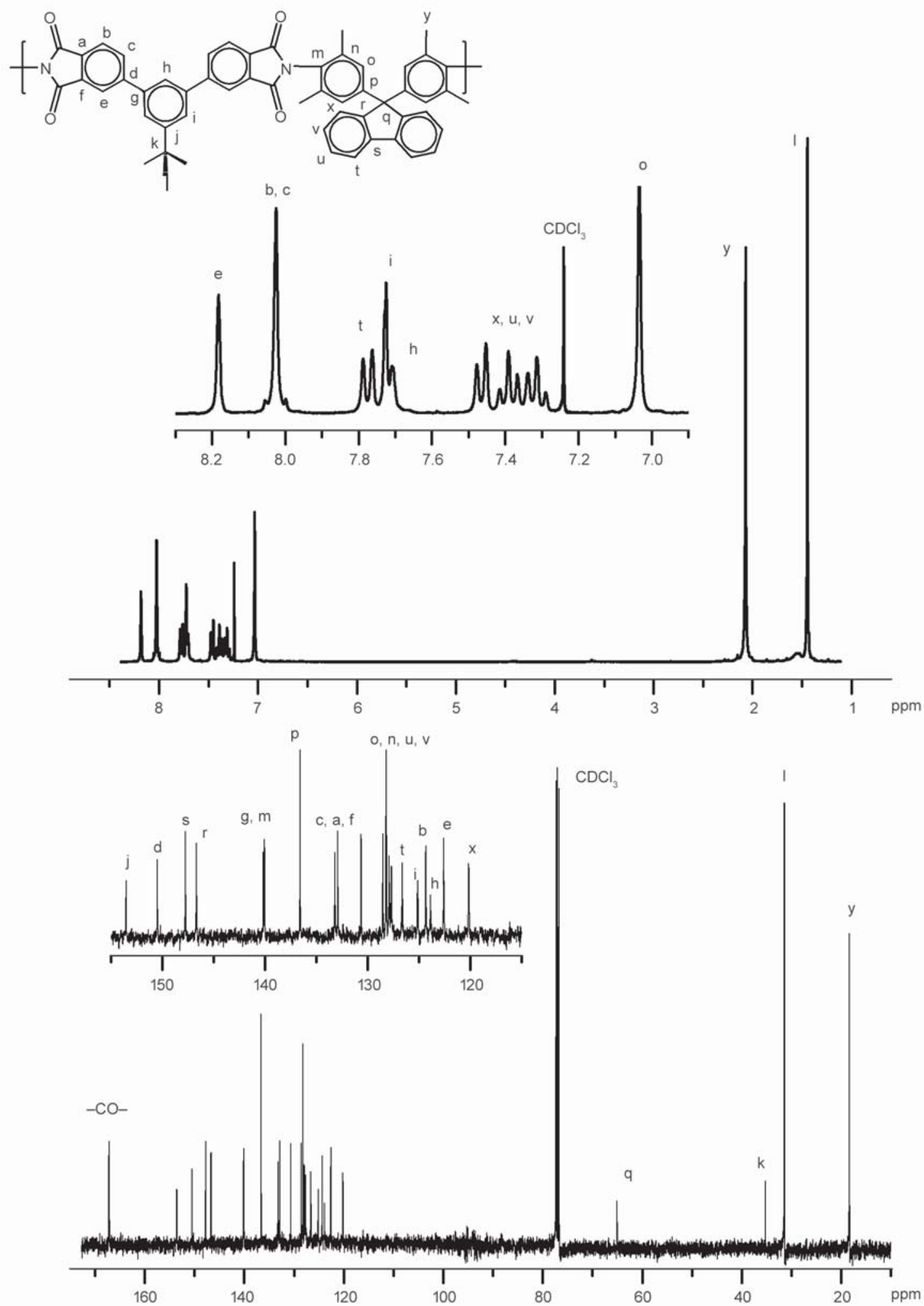

Figure 2. ${ }^{1} \mathrm{H}-\mathrm{NMR}$ and ${ }^{13} \mathrm{C}-\mathrm{NMR}$ spectra of polyimide BTPDA-TMeCardo. 
Regarding the aromatic diamines, those with cardo structure (Cardo and TMeCardo $)\left(E_{\mathrm{HOMO}}=-5.17\right.$ and $-5.02 \mathrm{eV}$ ) have similar reactivity and are less reactive than $p$-phenylendiamine $\left(E_{\mathrm{HOMO}}=-4.65 \mathrm{eV}\right), 4,4^{\prime}$ oxydianiline $\left(E_{\mathrm{HOMO}}=-4.86 \mathrm{eV}\right)$ or even Durene $\left(E_{\mathrm{HOMO}}=-4.43 \mathrm{eV}\right)$ or TMeMPD $\left(E_{\mathrm{HOMO}}=\right.$ $-4.39 \mathrm{eV})$. In fact, the last two diamines, because of the inductive effect of the methyl groups, are among the most reactive diamines in the synthesis of polyimides, if only electronic parameters are considered. In conclusion, the energy differences between the diamines used in this work and both dianhydrides, which are presented in columns 4 and 5 ( $\triangle E B T P D A$ amine and $\triangle E$ 6FDA-amine), are low enough to suppose that the polycondensation reactions will proceed to give high molecular weight polymers in all cases.

After evaluating the reactivity of the monomers, the synthesis of polyimides was performed through a one-pot method in solution at high temperature. The method involves the use of a high boiling point solvent ( $m$-cresol) in which the monomers are heated at high temperature $\left(180^{\circ} \mathrm{C}\right)$. In addition, basic and acid catalysts are usually employed to improve the reactivity. This procedure causes simultaneous polymerization and imidization and it is normally used to assure a high molecular weight in polyimides of elevated rigidity. The inherent viscosities of the synthesized polymers are shown in Table 2 . These values correspond to weight-average molecular weights of around $1 \cdot 10^{5}$ Dalton or higher [36]. As can be seen, in spite of the theoretically lower reactivity of the BTPDA, the polymers from this dianhydride show higher viscosities and, consequently, they have higher molecular weights. The steric effect of the ortho methyl groups of TMeCardo seems to cause a small shortcoming on the molecular weight.

All polymers were characterized by spectroscopic techniques, in particular FT-IR and NMR spectroscopy. The FT-IR spectra of the polyimide films contained absorption bands at approximately 1780 and $1720 \mathrm{~cm}^{-1}(\mathrm{C}=\mathrm{O}$ asymmetric and symmetric stretching), $1340 \mathrm{~cm}^{-1}$ (C-N stretching), $1105 \mathrm{~cm}^{-1}$ ( $\mathrm{C}-\mathrm{N}$ bending) and $725 \mathrm{~cm}^{-1}(\mathrm{C}=\mathrm{O}$ bending), and these bands are characteristic of imide rings. Typical aliphatic C-H absorption bands near 2940 $2860 \mathrm{~cm}^{-1}$ were also observed in the polymers with methyl or $t$-butyl groups. All the ${ }^{1} \mathrm{H}-\mathrm{NMR}$ signals were properly assigned (see the experimental part) and no signal corresponding to the poly(amic acid)
Table 2. Properties of novel cardo polyimides and reference polyimides.

\begin{tabular}{|l|c|c|c|c|}
\hline \multicolumn{1}{|c|}{ Polymer } & $\begin{array}{c}\mathbf{\eta} \\
{\left[\mathbf{d L} \cdot \mathbf{g}^{-\mathbf{1}} \mathbf{]}\right.}\end{array}$ & $\begin{array}{c}\mathbf{\rho} \\
{\left[\mathbf{g} \cdot \mathbf{c m}^{-3}\right]}\end{array}$ & $\begin{array}{c}\boldsymbol{T}_{\mathbf{g}} \\
{\left[{ }^{\circ} \mathbf{C}\right]}\end{array}$ & $\begin{array}{c}\boldsymbol{T}_{\mathbf{d}} \\
{\left[{ }^{\circ} \mathbf{C}\right]}\end{array}$ \\
\hline BTPDA-Cardo & 0.70 & 1.205 & 365 & 555 \\
\hline BTPDA-TMeCardo & 0.67 & 1.139 & 390 & 530 \\
\hline BTPDA-Durene & 0.69 & 1.193 & n.d. & 515 \\
\hline 6FDA-Cardo & 0.61 & 1.318 & 375 & 550 \\
\hline 6FDA-TMeCardo & 0.43 & 1.248 & 380 & 520 \\
\hline 6FDA-TMeMPD & 0.53 & 1.321 & 385 & 510 \\
\hline
\end{tabular}

structure was observed in any case, confirming the complete imidization. The carbons were also assigned by comparing the structures and by using additional DEPT and HMQC experiments. As an example, ${ }^{1} \mathrm{H}-\mathrm{NMR}$ and ${ }^{13} \mathrm{C}$-NMR spectra of polyimide BTPDA-TMeCardo are shown in Figure 2.

As could be expected, the aromatic protons near the imide ring appear at the highest values of chemical shift, because of the electron-withdrawing effect of the carbonyl groups: Conversely, the protons near the imide nitrogens appear at the lowest values of chemical shift as a singlet. The aliphatic protons of the methyl groups appear at $2.10 \mathrm{ppm}$ (methyl groups joined to the aromatic rings) and 1.46 (methyl groups of the t-butyl moiety). Regarding the ${ }^{13} \mathrm{C}$-NMR, the carbonyl carbons appear at $167.2 \mathrm{ppm}$, the methyl groups directly joined to the aromatic rings appear at $18.3 \mathrm{ppm}$, while those of $t$-butyl can be found at $31.4 \mathrm{ppm}$. The quaternary carbons of the $t$-butyl are at $35.2 \mathrm{ppm}$ and those corresponding to the fluorine bridge appear at $76.5 \mathrm{ppm}$. All the aromatic carbons can be found between 120 and $150 \mathrm{ppm}$.

\subsection{Polymers properties}

\subsubsection{Thermal properties}

The thermal behavior of the polyimides studied in this work was evaluated by DSC and TGA. Moreover, the amorphous character of these polymers was previously confirmed by WAXS, where an amorphous halo was visible in all the cases. The maximum in the amorphous halo corresponded to intersegmental distances between 5.6 and $6.5 \AA$, being slightly higher for the polymers derived from TBTPDA. However, it has not been possible to correlate the d-spacing with the chemical structure or with the fractional free volume. The polyimides showed high glass transition temperatures, above $350^{\circ} \mathrm{C}$, which is an indication of the high rigidity of these structures. The $T_{\mathrm{g}}$ of BTPDA-TMeCardo was $25^{\circ} \mathrm{C}$ higher than that of BTPDA-Cardo, denoting a higher molecular 


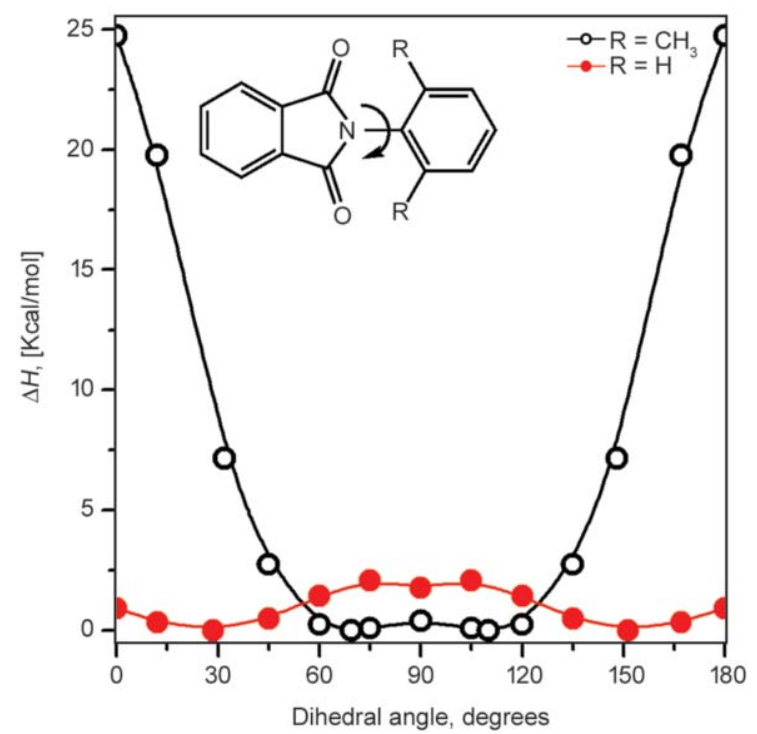

Figure 3. Rotational barriers, calculated by AM1, around the $N_{\text {imide }}-\mathrm{C}_{\mathrm{Ar}}$ bond for BTPDA-Cardo $(\bullet)$ and BTPDA-TMeCardo (०).

mobility restriction for this polymer. This fact can be explained by the steric effect that the ortho methyl groups caused in the phenyl moiety rotation. As can be seen in Figure 3, the calculated rotational barrier around the single bond joining the imide nitrogen and the aromatic ring is much higher in the case of the TMeCardo diamine. Because of that, the aromatic rings are restricted to a position almost perpendicular to the imide ones, with only a small amount of flipping between 60 and $120^{\circ}$. The high rotational barrier precludes the rotation around the bond, which is possible in the other cardo monomer, thus giving a considerably more rigid polymer.
All polyimides exhibited very high decomposition temperatures, $T_{\mathrm{d}_{\text {onset }}}$ above $520^{\circ} \mathrm{C}$. The values observed for the cardo polyimides were similar to that reported for the polyimide $B T P D A-6 F$ [33] indicating that the cardo moieties did not decrease the thermal resistance.

\subsubsection{Solubility}

The solubility of the polyimides was very similar irrespective of the dianhydride; $6 F D A$ or $B T P D A$, but it depended quite strongly on the diamine. Thus, the polyimide derived from the $p$-substituted Durene diamine was only soluble in $m$-cresol, $N$-methyl-2pyrrolidinone and hot dimethyl sulfoxide. However, the rest of the polyimides were also soluble in $N, N$ dimethylacetamide, $N, N$-dimethylformamide and chloroform. Moreover, the polyimides derived from Cardo and TMeCardo were soluble in dichloromethane and pyridine at room temperature. By contrast, the polyimide BTPDA-6F [33] was insoluble in $N, N$-dimethylformamide, chloroform, dichloromethane or pyridine. Therefore, the existence of cardo moieties, and additionally the presence of orthomethyl groups in $T M e M P D$, significantly improved the solubility, when compared with the $6 F$ diamine.

\subsubsection{Gas transport properties}

The gas permeation characteristics of the polyimides, together with the calculated fractional free volume are presented in Table 3.

The analysis of Table 3 permitted to obtain some interesting structure-properties relationships:

Table 3. Gas permeability coefficients (P), in Barrer, and ideal separation factors of novel and reference polyimides at $30^{\circ} \mathrm{C}$ and 3 bar.

\begin{tabular}{|c|c|c|c|c|c|c|c|c|c|c|}
\hline Polymer & PHe & $\mathrm{PO}_{2}$ & $\mathbf{P N}_{2}$ & $\mathrm{PCO}_{2}$ & $\mathrm{PCH}_{4}$ & $\alpha_{\mathrm{O}_{2} / \mathrm{N}_{2}}$ & $\alpha_{\mathrm{CO}_{2} / \mathrm{CH}_{4}}$ & $\alpha_{\mathrm{CO}_{2} / \mathrm{N}_{2}}$ & FFV & Ref. \\
\hline BTPDA-ODA & 33.0 & 5.1 & 0.97 & 25.0 & 0.96 & 5.30 & 25.6 & 25.8 & 0.132 & [37] \\
\hline$B T P D A-6 F$ & 115.0 & 24.2 & 5.80 & 114.0 & 5.00 & 4.20 & 22.9 & 19.7 & 0.187 & [37] \\
\hline BTPDA-Cardo & 45.0 & 9.9 & 2.00 & 50.0 & 2.10 & 5.00 & 24.0 & 25.0 & 0.140 & This work \\
\hline BTPDA-TMeCardo & 113.0 & 38.0 & 7.0 & 155.0 & 7.50 & 5.40 & 21.0 & 22.0 & 0.169 & This work \\
\hline BTPDA-Durene & 140.0 & 49.2 & 9.9 & 168.0 & 12.10 & 5.00 & 13.9 & 17.0 & 0.136 & This work \\
\hline BTPDA-TMeMPD & 247.0 & 111.0 & 30.0 & 465.0 & 39.80 & 3.70 & 11.7 & 15.5 & 0.182 & [38] \\
\hline 6FDA-ODA & 51.5 & 3.9 & 0.70 & 21.7 & 0.40 & 5.60 & 54.0 & 31.0 & 0.164 & [39] \\
\hline $6 F D A-6 F$ & 150.6 & 17.8 & 3.60 & 70.0 & 1.96 & 4.94 & 35.7 & 19.4 & 0.208 & [14] \\
\hline 6FDA-Cardo & 76.0 & 12.0 & 2.80 & 58.0 & 1.70 & 4.30 & 34.0 & 25.0 & 0.183 & This work \\
\hline 6FDA-TMeCardo & 177.0 & 59.0 & 13.00 & 217.0 & 7.50 & 4.50 & 29.0 & 17.0 & 0.200 & This work \\
\hline 6FDA-Durene & 362.0 & 125.1 & 35.60 & 456.0 & 28.40 & 3.50 & 16.1 & 12.8 & 0.180 & [40] \\
\hline 6FDA-TMeMPD & 473.0 & 164.0 & 46.00 & 630.0 & 37.00 & 3.70 & 17.0 & 13.7 & 0.218 & This work \\
\hline
\end{tabular}

1 Barrer $=10^{-10}\left(\mathrm{~cm}^{3}(\mathrm{STP}) \cdot \mathrm{cm}\right) /\left(\mathrm{cm}^{2} \cdot \mathrm{s} \cdot \mathrm{cmHg}\right)=3.346 \cdot 10^{-16} \mathrm{~mol} \cdot \mathrm{m} /\left(\mathrm{m}^{2} \cdot \mathrm{s} \cdot \mathrm{Pa}\right)($ SI units $)$. 
1) The polyimides derived from $6 F D A$ were more permeable than those derived from $B T P D A$ were, with the exception of the polyimides derived from $O D A$ and $6 F$. This can be correlated with the higher $F F V$ of the $6 F D A$ polymers.

2) The most permeable polymers were those having ortho methyl groups. For methyl diamines, the permeability for all gases followed the tendency: $P_{\mathrm{TMeMPD}}>P_{\text {Durene }}>P_{\mathrm{TMeC}}$ ardo. However, in this case, no correlation between permeability and $F F V$ was observed, because Durene polymers showed the smallest $F F V$ values.

3) The polymers derived from TMeCardo were more permeable than those derived from $6 F$ were, regardless of the employed dianhydride. However, the permeability differences depended strongly on the dianhydride. Thus, for the polymers derived from $6 F D A$, the polyimides from the TMeCardo diamine showed permeability values that are about 3-4 times higher than those derived from the diamine $6 F$, whereas for the polymers derived from $B P T D A$, the increase in permeability was only around 1.5 times. However, these differences could not be correlated with the $F F V$ values, because $F F V$ was higher for the polymers derived from $6 F$.

4) For common glassy polymers, the $\mathrm{CH}_{4}$ permeability is lower than the $\mathrm{N}_{2}$ permeability. However, when the $F F V$ of a polymer is high enough, an inversion of this behavior is frequently observed. Thus, the $\mathrm{PCH}_{4} / \mathrm{PN}_{2}$ reversal was seen in all the cardo and ortho-methyl diamines derived from $B T P D A$, but it did not occur in the $6 F D A$ derived polymers. This effect, which had been described previously [36] could not be related with the $F F V$, which was higher in the $6 F D A$ polymers. This fact could indicate that there were differences of free volume distribution for both series of polyimides, with a greater proportion of high free volume elements in the $B T P D A$ series. Because of this, the selectivity $\mathrm{CO}_{2} / \mathrm{N}_{2}$ was similar in both series but the selectivity $\mathrm{CO}_{2} / \mathrm{CH}_{4}$ was higher in the $6 F D A$ polyimides.

5) The increase in permeability in the TMeCardo polymers, when compared with the Cardo ones, is accompanied by an increase of permselectivity for the $\mathrm{O}_{2} / \mathrm{N}_{2}$ gas pair, and a very small selectivity lessening for the $\mathrm{CO}_{2} / \mathrm{CH}_{4}$ and the $\mathrm{CO}_{2} / \mathrm{N}_{2}$ gas pairs. Therefore, the incorporation of ortho methyl groups in the Cardo moiety was advantageous for
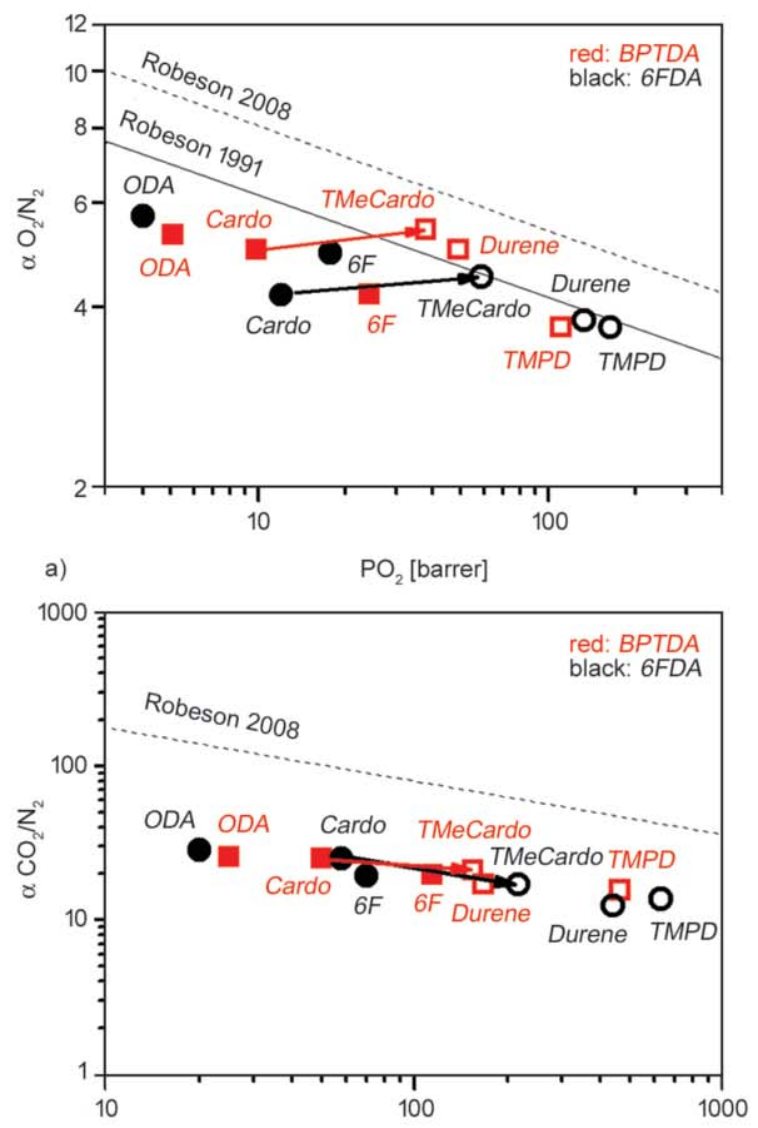

b) $\quad \mathrm{PO}_{2}[$ barrer $]$

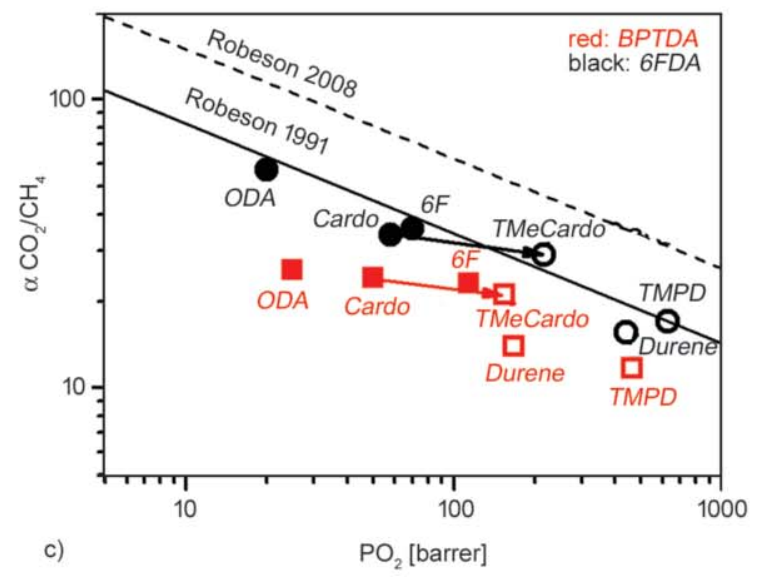

Figure 4. $\mathrm{O}_{2} / \mathrm{N}_{2}$ (a), $\mathrm{CO}_{2} / \mathrm{N}_{2}$ (b) and $\mathrm{CO}_{2} / \mathrm{CH}_{4}$ (c) productivities for the two series of polyimide membranes studied in this work. The lines represent the Robeson upper bounds of 1991 and 2008.

gas separation productivity since gas permeability was improved without sacrificing gas selectivity.

All these effects could be observed in the Robeson diagrams [41, 42] for the pairs $\mathrm{O}_{2} / \mathrm{N}_{2}, \mathrm{CO}_{2} / \mathrm{N}_{2}$ and $\mathrm{CO}_{2} / \mathrm{CH}_{4}$ shown in Figure 4 . The polymers derived from TMeCardo, Durene and TMeMPD diamines showed the best behavior, being placed near the Robeson upper bound of 1991. In the case of the 
$\mathrm{O}_{2} / \mathrm{N}_{2}$ and $\mathrm{CO}_{2} / \mathrm{N}_{2}$ gas pairs, the behavior was similar for $6 F D A$ and BTPDA dianhydrides. However, for the pair $\mathrm{CO}_{2} / \mathrm{CH}_{4}$, the BTPDA polyimides showed a lower selectivity caused by the high permeability of $\mathrm{CH}_{4}$ observed in these polymers $\left(\mathrm{PCH}_{4} / \mathrm{PN}_{2}\right.$ reversal). Consequently, the polymer $6 F D A-T M e$ Cardo was the best polymer, and overpassed the 1991 upper bound.

\section{Conclusions}

Some novel polyimides have been obtained, through the use of the one-pot method in solution at high temperature, by reacting a $m$-terphenyl dianhydride containing tert-butyl pendent groups $(B T P D A)$ or the commercial $6 F D A$ dianhydride with four diamines, two commercial ones bearing methyl groups placed ortho to the amino functionality, and two cardo ones, one of which bears also ortho methyl groups. All of them showed $T_{\mathrm{g}} \mathrm{s}$ above $350^{\circ} \mathrm{C}$, because of the effect of the hindered dianhydrides, the ortho methyl groups or the cardo moieties. Furthermore, the methyl groups also provided very good solubility, which was excellent for the polyimides made from the TMeCardo diamine. The thermal stability of these polyimides was also very high with degradation temperatures above $500^{\circ} \mathrm{C}$ in all cases.

Regarding the gas separation properties, the 5'-tertbutyl- $m$-terphenyl moiety produced polymers with lower permeability than those derived from $6 F D A$. The ortho-methyl substitutions had a significant effect on permeability, which was clearly seen when the Cardo and the TMeCardo polymers were compared. In that case, a significant improvement of performance for the pairs $\mathrm{O}_{2} / \mathrm{N}_{2}$ and $\mathrm{CO}_{2} / \mathrm{CH}_{4}$ was observed, which permitted some of these polymers to be placed between the 1991 and the 2008 Robeson limits.

A permeability inversion was found for the pair $\mathrm{N}_{2} / \mathrm{CH}_{4}$ in the case of BTPDA-derived polyimides, but not for those derived from $6 F D A$, which seemed to imply the existence of different free volume distribution in the polyimides derived from both dianhydrides.

\section{Acknowledgements}

The financial support of this work by the Spanish Ministry of Economy and Competitiveness (MINECO) (MAT201345071, CTQ2013-48406-P, MAT2016-76413-C2-R2) is greatly appreciated.

\section{References}

[1] Sroog C. E.: Polyimides. Progress in Polymer Science, 16, 561-694 (1991). https://doi.org/10.1016/0079-6700(91)90010-I

[2] de Abajo J., de la Campa J.: Processable aromatic polyimides. in 'Progress in polyimide chemistry I, Advances in polymer science' (ed.: Kricheldorf H. R.) Springer, Berlin, Vol. 140, 23-59 (1999). https://doi.org/10.1007/3-540-49815-X_2

[3] Ghosh M. K., Mittal K. L.: Polyimides: Fundamentals and applications. Marcel Dekker, New York (1996).

[4] Baker R. W.: Future directions of membrane gas separation technology. Industrial Engineering Chemical Research, 41, 1393-1411 (2002). https://doi.org/10.1021/ie0108088

[5] Yampolskii Y.: Polymeric gas separation membranes. Macromolecules, 45, 3298-3311 (2012). https://doi.org/10.1021/ma300213b

[6] Lv X., Li L., Tang S., Wang C., Zhao X.: High $\mathrm{CO}_{2} / \mathrm{N}_{2}$ and $\mathrm{CO}_{2} / \mathrm{CH}_{4}$ selectivity in a chiral metal-organic framework with contracted pores and multiple functionalities. Chemical Communications, 2014, 6886-6889 (2014). https://doi.org/10.1039/c4cc00334a

[7] Xiao Y., Low B. T., Hosseini S. S., Chung T. S., Paul D. R.: The strategies of molecular architecture and modification of polyimide-based membranes for $\mathrm{CO}_{2}$ removal from natural gas-A review. Progress in Polymer Science, 34, 561-580 (2009). https://doi.org/10.1016/j.progpolymsci.2008.12.004

[8] Ding M.: Isomeric polyimides. Progress in Polymer Science, 32, 623-668 (2007). https://doi.org/10.1016/j.progpolymsci.2007.01.007

[9] Calle M., Lozano A. E., de la Campa J. G., de Abajo J.: Novel aromatic polyimides derived from $5^{\prime}-t$-butyl-2'pivaloylimino-3,4,3",4"-m-terphenyltetracarboxylic dianhydride with potential application on gas separation processes. Macromolecules, 43, 2268-2275 (2010). https://doi.org/10.1021/ma901943j

[10] Wiegand J. R., Smith Z. P., Liu Q., Patterson C. T., Freeman B. D., Guo R.: Synthesis and characterization of triptycene-based polyimides with tunable high fractional free volume for gas separation membranes. Journal of Materials Chemistry A, 2, 13309-13320 (2014). https://doi.org/10.1039/C4TA02303J

[11] Robeson L. M., Freeman B. D., Paul D. R., Rowe B. W.: An empirical correlation of gas permeability and permselectivity in polymers and its theoretical basis. Journal of Membrane Science, 341, 178-185 (2009). https://doi.org/10.1016/j.memsci.2009.06.005

[12] Freeman B. D.: Basis of permeability/selectivity tradeoff relations in polymeric gas separation membranes. Macromolecules, 32, 375-380 (1999).

https://doi.org/10.1021/ma9814548 
[13] Ayala D., Lozano A. E., de Abajo J., García-Perez C., de la Campa J. G., Peinemann K-V., Freeman B. D., Prabhakar R.: Gas separation properties of aromatic polyimides. Journal of Membrane Science, 215, 61-73 (2003). https://doi.org/10.1016/S0376-7388(02)00602-6

[14] Calle M., Lozano A. E., de Abajo J., de la Campa, J. G., Álvarez C.: Design of gas separation membranes derived of rigid aromatic polyimides. 1. Polymers from diamines containing di-tert-butyl side groups. Journal of Membrane Science, 365, 145-153 (2010). https://doi.org/10.1016/j.memsci.2010.08.051

[15] Kazama S., Teramoto T., Haraya K.: Carbon dioxide and nitrogen transport properties of bis(phenyl)fluorenebased cardo polymer membranes. Journal of Membrane Science, 207, 91-104 (2002).

https://doi.org/10.1016/S0376-7388(02)00112-6

[16] Espeso J. F., Lozano A. E., de la Campa J. G., GarcíaYoldi I., de Abajo J.: Synthesis and properties of new aromatic polyisophthalamides with adamantylamide pendent groups. Journal of Polymer Science Part A: Polymer Chemistry, 48, 1743-1751 (2010).

https://doi.org/10.1002/pola.23939

[17] Kim Y-H., Ahn S-K., Kim H. S., Kwon S-K.: Synthesis and characterization of new organosoluble and gas-permeable polyimides from bulky substituted pyromellitic dianhydrides. Journal of Polymer Science Part A: Polymer Chemistry, 40, 4288-4296 (2002).

https://doi.org/10.1002/pola.10493

[18] Bandyopadhyay P., Bera D., Ghosh S., Banerjee S.: Ditert-butyl containing semifluorinated poly(ether amide)s: Synthesis, characterization and gas transport properties. Journal of Membrane Science, 447, 413-423 (2013). https://doi.org/10.1016/j.memsci.2013.07.050

[19] Ayala D., Lozano A. E., de Abajo J., de la Campa J. G.: Synthesis and characterization of novel polyimides with bulky pendant groups. Journal of Polymer Science Part A: Polymer Chemistry, 37, 805-814 (1999). https://doi.org/10.1002/(SICI)10990518(19990315)37:6<805::AID-POLA16>3.0.CO;2-9

[20] Maya E. M., Muñoz D. M., de la Campa J. G., de Abajo J., Lozano A. E.: Thermal effect on polyethyleneoxidecontaining copolyimide membranes for $\mathrm{CO}_{2} / \mathrm{N}_{2}$ separation. Desalination, 199, 188-190 (2006).

https://doi.org/10.1016/j.desal.2006.03.042

[21] Bisoi S., Bandyopadhyay P., Bera D., Banerjee S.: Effect of bulky groups on gas transport properties of semifluorinated poly(ether amide)s containing pyridine moiety. European Polymer Journal, 66, 419-428 (2015).

https://doi.org/10.1016/j.eurpolymj.2015.03.008

[22] Maya E. M., Lozano A. E., de Abajo J., de la Campa J. G.: Chemical modification of copolyimides with bulky pendent groups: Effect of modification on solubility and thermal stability. Polymer Degradation and Stability, 92, 2294-2299 (2007).

https://doi.org/10.1016/j.polymdegradstab.2007.01.042
[23] Kazama S., Teramoto T., Haraya K.: Oxygen separation properties of bis(phenyl)fluorene-based cardo polymer membranes. High Performance Polymers, 17, 3-17 (2005). https://doi.org/10.1177/0954008305039015

[24] Fang X., Wang Z., Yang Z., Gao L., Li Q., Ding M.: Novel polyimides derived from 2,3,3',4'-benzophenonetetracarboxylic dianhydride. Polymer, 44, 2641-2646 (2003). https://doi.org/10.1016/S0032-3861(03)00181-2

[25] Sridhar S., Veerapur R. S., Patil M. B., Gudasi K. B., Aminabhavi T. M.: Matrimid polyimide membranes for the separation of carbon dioxide from methane. Journal of Applied Polymer Science, 106, 1585-1594 (2007). https://doi.org/10.1002/app.26306

[26] Wang X., Liu F., Lai J., Fu Z., You X.: Comparative investigations on the effects of pendent trifluoromethyl group to the properties of the polyimides containing diphenyl-substituted cyclopentyl cardo-structure. Journal of Fluorine Chemistry, 164, 27-37 (2014).

https://doi.org/10.1016/j.jfluchem.2014.04.016

[27] Yeong Y. F., Wang H., Pallathadka Pramoda K., Chung T-S.: Thermal induced structural rearrangement of cardo-copolybenzoxazole membranes for enhanced gas transport properties. Journal of Membrane Science, 397-398, 51-65 (2012).

https://doi.org/10.1016/j.memsci.2012.01.010

[28] Liaw D-J., Liaw B-Y.: Synthesis and characterization of new soluble cardo polyamides derived from 2,2-bis [4-(4-carboxyphenoxy)phenyl]norbornane. Polymer Journal, 33, 204-208 (2001). https://doi.org/10.1295/polymj.33.204

[29] Camacho-Zuñiga C., Ruiz-Treviño F. A., Zolotukhin M. G., del Castillo L. F., Guzman J., Chavez J., Torres G., Gileva N. G., Sedova E. A.: Gas transport properties of new aromatic cardo poly(aryl ether ketone)s. Journal of Membrane Science, 283, 393-398 (2006). https://doi.org/10.1016/j.memsci.2006.07.013

[30] Terraza C. A., Liu J-G., Nakamura Y., Shibasaki Y., Ando S., Ueda M.: Synthesis and properties of highly refractive polyimides derived from fluorene-bridged sulfurcontaining dianhydrides and diamines. Journal of Polymer Science Part A: Polymer Chemistry, 46, 1510-1520 (2008). https://doi.org/10.1002/pola.22492

[31] Carta M., Croad M., Jansen J. C., Bernardo P., Clarizia G., McKeown N. B.: Synthesis of cardo-polymers using Tröger's base formation, 5, 5255-5261 (2014). https://doi.org/10.1039/C4PY00607K

[32] Maya E. M., Muñoz D. M., Lozano A. E., de Abajo J., de la Campa J. G.: Fluorenyl cardo copolyimides containing poly(ethylene oxide) segments: Synthesis, characterization, and evaluation of properties. Journal of Polymer Science Part A: Polymer Chemistry, 46, 81708178 (2008). https://doi.org/10.1002/pola.23114 
[33] García C., Lozano A. E., de la Campa J. G., de Abajo J.: Soluble polyimides from a new dianhydride: 5 '-tert-butyl$m$-terphenyl-3,4,3",4"-tetracarboxylic acid dianhydride. Macromolecular Rapid Communications, 24, 686-691 (2003).

https://doi.org/10.1002/marc.200350014

[34] Dewar M. J. S., Zoebisch E. G., Healy E. F., Stewart J. J. P.: Development and use of quantum mechanical molecular models. 76. AM1: A new general purpose quantum mechanical molecular model. Journal of the American Chemical Society, 107, 3902-3909 (1985). https://doi.org/10.1021/ja00299a024

[35] Zhang I. Y., Wu J., Xu X.: Extending the reliability and applicability of B3LYP. Chemical Communications, 46, 3057-3070 (2010). https://doi.org/10.1039/c000677g

[36] Álvarez C., Lozano A. E., de la Campa J. G.: High-productivity gas separation membranes derived from pyromellitic dianhydride and nonlinear diamines. Journal of Membrane Science, 501, 191-198 (2016). https://doi.org/10.1016/j.memsci.2015.11.039

[37] de Abajo J., de la Campa J. G., Lozano A. E., Espeso J., García C.: Designing aromatic polyamides and polyimides for gas separation membranes. Macromolecular Symposia, 199, 293-306 (2003).

https://doi.org/10.1002/masy.200350925
[38] Calle M., García C., Lozano A. E., de la Campa J. G., de Abajo J., Álvarez C.: Local chain mobility dependence on molecular structure in polyimides with bulky side groups: Correlation with gas separation properties. Journal of Membrane Science, 434, 121-129 (2013). https://doi.org/10.1016/j.memsci.2013.01.054

[39] Coleman M. R., Koros W. J.: Isomeric polyimides based on fluorinated dianhydrides and diamines for gas separation applications. Journal of Membrane Science, 50, 285-297 (1990). https://doi.org/10.1016/S0376-7388(00)80626-2

[40] Lin W-H., Chung T-S.: Gas permeability, diffusivity, solubility, and aging characteristics of 6FDA-durene polyimide membranes. Journal of Membrane Science, 186, 183-193 (2001). https://doi.org/10.1016/S0376-7388(01)00333-7

[41] Robeson L. M.: Correlation of separation factor versus permeability for polymeric membranes. Journal of Membrane Science, 62, 165-185 (1991). https://doi.org/10.1016/0376-7388(91)80060-J

[42] Robeson L. M.: The upper bound revisited. Journal of Membrane Science, 320, 390-400 (2008) https://doi.org/10.1016/j.memsci.2008.04.030 